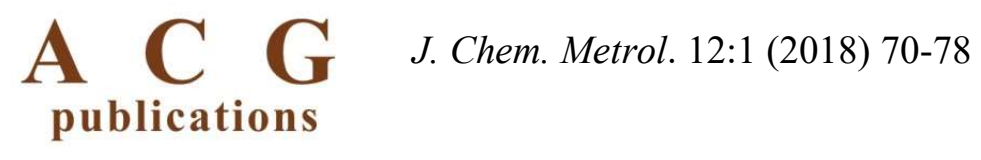

journal of chemical metrology

\title{
Determination of sulfonamides in milk by ID-LC-MS/MS
}

\author{
Isin Aydin Unsal ${ }^{*}{ }^{1}$, Murat Tasan $\odot^{1}$,Taner Gokcen $\odot^{2}$ and Ahmet C. Goren $\odot^{3}$ \\ ${ }^{1}$ Namik Kemal University, Department of Food Engineering, P.O. Box 59030, Merkez Tekirdag, Türkiye \\ ${ }^{2}$ TUBITAK UME, Organic Chemistry Laboratory, PK 54, 41470, Gebze Kocaeli, Türkiye \\ ${ }^{3}$ Bezmialem Vakif University, Faculty of Pharmacy, Department of Analytical Chemistry,34093, Fatih- \\ Istanbul, Türkiye
}

(Received April 29, 2018; Revised May 23, 2018; Accepted May 24, 2018)

\begin{abstract}
In this study, an ID-LC-MS method was developed and validated for the determination of 14 sulfonamides in milk samples. Recovery results were found to be in the range of $91 \%-114 \%$ for milk samples. The relative measurement uncertainty was between $7.5 \%$ - 12.7\%. Validated method was performed on milk samples obtained from market and street vendors. The amount of sulfonamides in the analyzed samples was found to be below the legal limits (Sulfamethazine: $6.46 \pm 0.76 \mathrm{ng} / \mathrm{g}$ and sulfisoxazole: $7.3 \pm 0.71 \mathrm{ng} / \mathrm{g}$ ).
\end{abstract}

Keywords: Sulfonamides; isotope dilution; LC-MS/MS, method validation; uncertainty estimation. C 2018 ACG Publications. All rights reserved.

\section{Introduction}

Antibacterial sulfonamides (SAs), in general called as "sulfa drugs", are a group of synthetic antibacterial agents that comprise sulfonamide group and widely used in veterinary practice for the treatment of infections and growth of animals that produce food. Due to their low cost, low toxicity, and excellent antibacterial properties against common bacterial diseases make them popular agents [1]. However, uncontrolled use of veterinary drugs and noncompliance with the withdrawal period pave the way for drug residues to remain in animal tissues and transfer into their milk [2-4]. Sulfonamide residues in food is an important issue as they possess a potential risk toward human health by inducing drug-resistant pathogenic strains of bacteria, toxicity and allergic reactions $[2,4-6]$. Thus, European Union Commission Regulation 37/2010/EEC and Republic of Turkey, Ministry of Food, Agriculture and Livestock announcement No 2011/20 have set the maximum residue limits (MRLs) for total SAs in milk as $100 \mu \mathrm{g} / \mathrm{kg}[7,8]$.

The methods reported in the literature for the determination of sulfonamide residues comprise enzymelinked immunosorbent assay (ELISA) [9,10], capillary electrophoresis [11,12], high performance liquid chromatography (HPLC) coupled with diode array detection (DAD)/ florescence detection (FLD) [13-16], gas chromatography-mass spectrometry (GC-MS) [17,18], liquid chromatography-tandem mass spectrometry (LC-MS/MS) [2,19-21] and liquid chromatography-high resolution mass spectrometry (LCHRMS) [20,22]. In order to fulfill the requirements of food safety regulations, methods developed to determine sulfonamide residues in milk should be sensitive, selective and capable of detecting the residues below the maximum residue limits (MRL). Microbiological assays are quick, inexpensive, selective but

\footnotetext{
* Corresponding author: E-Mail: isin aydin07@hotmail.com
} 
Aydin Unsal et al., J. Chem.Metrol. 12:1 (2018) 70-78

lacking of structural information that might produce false positive results [2]. LC-MS/MS has become most appropriate method for the residue analysis with its high selectivity, sensitivity, decisiveness and its applicability to determine the polar and/or non-volatile compounds without derivatization, including both electrospray and atmospheric pressure chemical ionization methods [18].

In recent years, although determination of multiclass veterinary drugs in one method has become more popular, they are compromising from the accuracy of the analytes. This study is focused especially on isotope dilution-liquid chromatography mass spectrometry (ID-LCMS) technique because of its high performance on accuracy and repeatability. In IDMS technique, isotopically labelled analogues of all compounds are added to the sample before the extraction processes and allowed to reach equilibrium without any loss or isotopic fractionation. It eliminates all errors at all stages of the method. IDMS technique traceable to International System of Units is a primary method and it is an acceptable alternative to estimate "true value" in the absence of a certified reference material (CRM) [23,24]. IDMS provides high accuracy and precision compared with internal standard addition or external calibration techniques [24].

None of the methods in the literature reported a full IDMS technique for the determination of sulfonamide residues in milk. The available methods provide only 1-3 isotopically labelled sulfonamides to be used as internal standards [25-32]. This study describes the development and validation of a full IDMS technique for all 14 sulfonamides in milk. In order to ensure the reliability of the developed method, recovery, accuracy, precision, LOD and LOQ, intraday and interday repeatability, linearity, robustness were estimated based on the analyses of spiked milk samples. The measurement uncertainty was evaluated by using "top-down approach" as described by EURACHEM CITAC Guide [33] and ISO 21748:2017 [34].

Milk comprises rich proteins and lipids, which make it a complex matrix for extraction and clean up to determine veterinary drugs in it. Different extraction methods have been proposed in the literature for sample preparation and clean-up for the determination of sulfonamides, such as liquid-liquid extraction (LLE) [25], solid-phase extraction (SPE) [5], solid-phase microextraction (SPME) [35], molecularly imprinted polymer extraction [36], pressurized liquid extraction (PLE) [37], QuEChERS [38], cloud point extraction (CPE) [39] and dispersive micro solid-phase extraction [40]. In this study a liquid-liquid extraction was employed, which greatly reduced the operation time and cost. The sulfonamides were extracted from milk samples using acetonitrile:ethyl acetate (6:4) solvent mixture. It was stirred employing a vortex, after which the mixture was centrifuged to separate proteins. The upper layer was separated by pipette and the solvent was evaporated by applying a gentle stream of nitrogen. The residue was vortexed after addition of hexane to remove fat content, after which sulfonamides were transferred into a $10 \%$ methanol/water mixture. An aliquot from bottom part (methanol:water) was analyzed by LC-MS/MS.

\section{Experimental}

\subsection{Chemicals and Reagents}

Acetonitrile, ethyl acetate, methanol and n-hexane were LC or GC grade and supplied from Merck (USA). Formic acid was purchased from Fluka (USA). Ultrapure water was generated by ELGA water purification system. Sulfathiazole (STZ), sulfapyridine (SPD), sulfamethazine (SMZ), sulfamerazin (SMR), sulfadiazine (SDZ), sulfadimethoxine (SDM), sulfamethoxazole (SMX), sulfadoxine (SDX), sulfisoxazole (SSX), sulfaphenazole (SPA), sulfaquinoxaline (SQX), sulfachloropyridazine (SCP), sulfamethizole (SME), sulfamethoxypyridazine (SMP), sulfamethoxypyridazine- $\mathrm{d}_{3}$, sulfamethizole-(phenyl- ${ }^{13} \mathrm{C}_{6}$ ), sulfadoxine- $\mathrm{d}_{3}$, sulfaquinoxaline-(phenyl- ${ }^{13} \mathrm{C}_{6}$ ), sulfaphenazole-(phenyl- $\left.{ }^{13} \mathrm{C}_{6}\right)$, sulfapyridine-(phenyl- ${ }^{13} \mathrm{C}_{6}$ ) and sulfadimethoxine-(phenyl- ${ }^{13} \mathrm{C}_{6}$ ) were purchased from Sigma Aldrich. Sulfathiazole- $\mathrm{d}_{4}$, sulfamethazine- $\mathrm{d}_{4}$, sulfamerazine- $\mathrm{d}_{4}$, sulfadiazine- $\mathrm{d}_{4}$, sulfamethoxazole- $\mathrm{d}_{4}$, sulfisoxazole- $\mathrm{d}_{4}$ and sulfachloropyridazine- $\mathrm{d}_{4}$ were synthesized in TUBITAK UME Organic Chemistry Laboratory and characterized by NMR and HPLC/DAD.

Stock solutions of single analytes were prepared gravimetrically at a concentration of $1000 \mathrm{ng} / \mathrm{g}$ in methanol at Mettler Toledo XP205 balance (d:0.01 mg) and stored at $4{ }^{\circ} \mathrm{C}$. Mixed standard solutions were prepared by dilution of stock solutions with methanol gravimetrically and stored at $4{ }^{\circ} \mathrm{C}$. Working solutions were prepared freshly by methanol:water (1:9) mixture. 
Table 1. MS parameters of sulfonamide compounds

\begin{tabular}{|c|c|c|c|c|c|}
\hline Sulfonamides & $\begin{array}{c}\text { Parent } \\
\text { Ion }\end{array}$ & $\begin{array}{c}\text { Quantitative } \\
\text { Ion }\end{array}$ & $\begin{array}{c}\text { Capillary } \\
\text { Energy }\end{array}$ & $\begin{array}{c}\text { Collision } \\
\text { Energy }\end{array}$ & $\begin{array}{l}\text { Retention } \\
\text { Time (min) }\end{array}$ \\
\hline Sulfamethizole & 271 & 156 & 100 & 12 & 14.401 \\
\hline Sulfamethazine & 279 & 186 & 110 & 20 & 14.014 \\
\hline Sulfachloropyridazine & 284.9 & 156 & 100 & 14 & 15.909 \\
\hline Sulfaquinoxaline & 301 & 156 & 100 & 15 & 19.246 \\
\hline Sulfadoxine & 311 & 156 & 100 & 18 & 16.305 \\
\hline Sulfadimethoxine & 311 & 156 & 100 & 20 & 19.048 \\
\hline Sulfapyridine & 250 & 156 & 100 & 20 & 12.895 \\
\hline Sulfadiazin & 251 & 156 & 80 & 15 & 11.349 \\
\hline Sulfamethoxazole & 254 & 156 & 80 & 18 & 16.681 \\
\hline Sulfathiazole & 256 & 155.9 & 80 & 14 & 12.127 \\
\hline Sulfamerazine & 265 & 156 & 80 & 20 & 13.172 \\
\hline Sulfisoxazole & 268 & 156 & 80 & 10 & 17.335 \\
\hline Sulfaphenazole & 315 & 160 & 60 & 20 & 19.745 \\
\hline Sulfamethoxypyridazine & 281 & 155.9 & 100 & 17 & 14.434 \\
\hline Sulfamethizole $-{ }^{13} \mathrm{C}_{6}$ & 276.9 & 161.9 & 100 & 12 & 14.398 \\
\hline Sulfamethazine- $\mathrm{d}_{4}$ & 283 & 186 & 110 & 18 & 13.953 \\
\hline Sulfachloropyridazine- $\mathrm{d}_{4}$ & 289 & 160 & 100 & 14 & 15.863 \\
\hline Sulfaquinoxaline $-{ }^{13} \mathrm{C}_{6}$ & 307 & 161.9 & 100 & 15 & 19.243 \\
\hline Sulfadoxine- $d_{3}$ & 314 & 155.9 & 100 & 16 & 16.241 \\
\hline Sulfadimethoxine $-{ }^{13} \mathrm{C}_{6}$ & 317 & 155.9 & 100 & 20 & 19.055 \\
\hline Sulfapyridine $-{ }^{13} \mathrm{C}_{6}$ & 256 & 113.9 & 100 & 16 & 12.135 \\
\hline Sulfadiazin- $\mathrm{d}_{4}$ & 255 & 160 & 80 & 15 & 11.262 \\
\hline Sulfamethoxazole- $\mathrm{d}_{4}$ & 258 & 160 & 80 & 16 & 16.630 \\
\hline Sulfathiazole- $\mathrm{d}_{4}$ & 260 & 160 & 80 & 14 & 12.039 \\
\hline Sulfamerazine- $\mathrm{d}_{4}$ & 269 & 160 & 80 & 18 & 13.091 \\
\hline Sulfisoxazole- $\mathrm{d}_{4}$ & 272 & 160 & 80 & 13 & 17.279 \\
\hline Sulfaphenazole $-{ }^{13} \mathrm{C}_{6}$ & 321 & 158 & 60 & 22 & 19.746 \\
\hline Sulfamethoxypyridazine- $\mathrm{d}_{3}$ & 284 & 128.9 & 100 & 16 & 14.391 \\
\hline
\end{tabular}



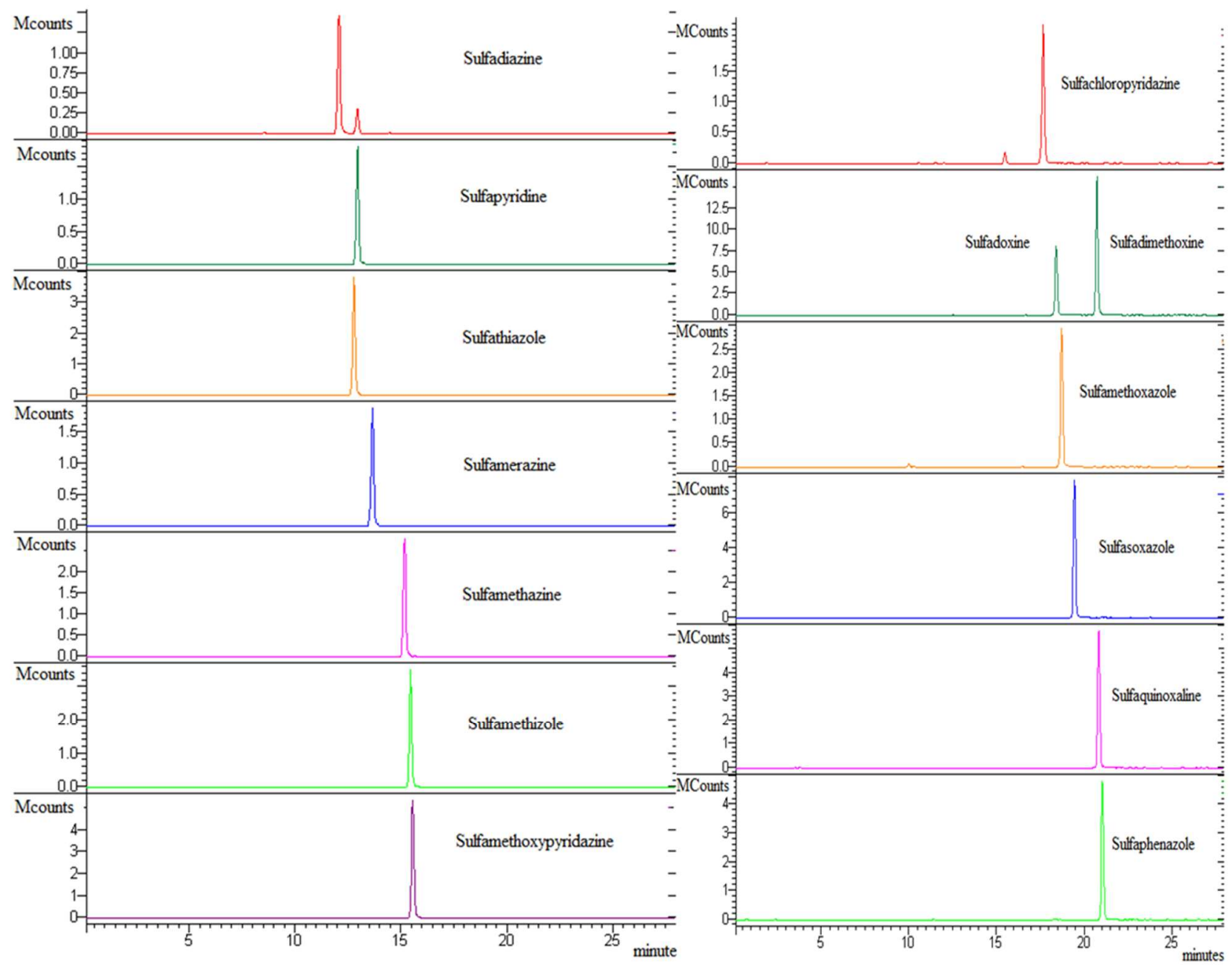

Figure 1. LC-MS/MS chromatogram of sulfonamides at $20 \mathrm{ng} / \mathrm{g}$ level.

\subsection{Instrumentation}

Analyzes were performed by ZIVAK Tandem Gold LC-MS-MS equipped with triple quadrupole analyzer and heated electro spray ionization source. Detector was $1600 \mathrm{~V}$, needle voltage was $5500 \mathrm{~V}$, spray shield voltage was $600 \mathrm{~V}$, spray chamber temperature was $55^{\circ} \mathrm{C}$, drying gas temperature was $350^{\circ} \mathrm{C}$, vortex gas temperature was $120^{\circ} \mathrm{C}$, nebulizing gas pressure was $50 \mathrm{psi}$, drying gas pressure was $30 \mathrm{psi}$ and vortex gas pressure was $25 \mathrm{psi}$. The analytical column was Phenomenex Synergi 4u Max RP 80A (250 mm X 3 $\mathrm{mm}, 4 \mu \mathrm{m})$. Column oven temperature was kept at $25^{\circ} \mathrm{C}$. The mobile phases were $0.1 \%(\mathrm{v} / \mathrm{v})$ formic acid in water-acetonitrile $(95: 5 \mathrm{v} / \mathrm{v})(\mathrm{A})$ and $0.1 \%(\mathrm{v} / \mathrm{v})$ formic acid in water-acetonitrile $(5: 95 \mathrm{v} / \mathrm{v})(\mathrm{B})$. A $30 \mathrm{~min}$ gradient of the LC method was set as follows $(0-0.5 \mathrm{~min}) 95 \% \mathrm{~A}$ and $5 \% \mathrm{~B},(0.5-6 \mathrm{~min}) 85 \% \mathrm{~A}$ and $15 \% \mathrm{~B}$, (6-12 min, hold $4 \mathrm{~min}) 65 \% \mathrm{~A}$ and $35 \% \mathrm{~B},(16-18 \mathrm{~min}$, hold $3 \mathrm{~min}) 45 \% \mathrm{~A}$ and $55 \% \mathrm{~B},(21-22 \mathrm{~min}$, hold 8 min) $95 \% \mathrm{~A}$ and $5 \% \mathrm{~B}$. MRM method details of the analytes are given in Table 1, and a representative chromatogram at $20 \mathrm{ng} / \mathrm{g}$ level is given in Figure 1. 


\subsection{Sample Preparation Procedure}

Five $\mathrm{mL}$ milk sample was transferred into a $50 \mathrm{~mL}$ polypropylene centrifuge tube and spiked with internal standard solution. After the addition of $10 \mathrm{~mL} \mathrm{ACN}: \mathrm{EA}(6: 4)(\mathrm{v} / \mathrm{v})$, the mixture was well mixed using a vortex and then centrifuged at $10000 \mathrm{rpm}$ for $10 \mathrm{~min}$. After centrifugation, $6 \mathrm{~mL}$ of the supernatant from the top was transferred to a clean $15 \mathrm{~mL}$ centrifuge tube and dried thoroughly under a gentle nitrogen stream. $1.5 \mathrm{~mL}$ of $\mathrm{n}$-hexane was added into the centrifuge tube and vortexed for 1 minute, then $1.5 \mathrm{~mL}, 10 \%$ $(\mathrm{v} / \mathrm{v})$ aqueous $\mathrm{MeOH}$ was added and vortexed for 1 minute. $1 \mathrm{~mL}$ from the bottom part of the biphasic solution was centrifuged at $14000 \mathrm{rpm}$ for 5 minutes, after which $500 \mu \mathrm{L}$ from the top layer was transferred to a $\mathrm{LC}$ vial for analysis.

\subsection{Method Validation}

The method validation was performed by spiking blank milk with a working solution. Matrix-matched calibration standards were prepared by spiking on blank extracts $(10,15,20,30,40,50 \mathrm{ng} / \mathrm{g}$, each contained $20 \mathrm{ng} / \mathrm{g}$ of ISTD) to generate six-point calibration curve, which was plotted by peak area ratio (analyte/ISTD) versus concentration ratio (analyte/ISTD). The LOD and LOQ values of the individual analytes were estimated from the standard deviation of 10 samples prepared by spiking blank samples with sulfonamides ( $10 \mathrm{ng} / \mathrm{g}$ of analyte and $20 \mathrm{ng} / \mathrm{g}$ of ISTD). LOD was estimated as 3 times of standard deviation and LOQ as 10 times of standard deviation. The precision and accuracy were expressed as RSD and recoveries. The recoveries of all analytes were calculated by the measured content/the fortified level times 100 . The linearity of the measurements in the range of $10-50 \mathrm{ng} / \mathrm{g}$ was evaluated by applying a linear regression analysis. The robustness of the method was investigated with the amount of acetonitrile, milk and hexane. Measurement uncertainties of the analytes were estimated according to EUROCHEM/CITAC and ISO measurement uncertainty description guideline (GUM).

\section{Results and discussion}

\subsection{Optimization of Spectrometry and LC Conditions}

Since MS/MS fragmentation of sulfonamides generally results in $\mathrm{m} / \mathrm{z} 156$, and LC/MS/MS used in this study is not of high resolution, we had the issue of separation for closer MW analytes and their ISTDs such

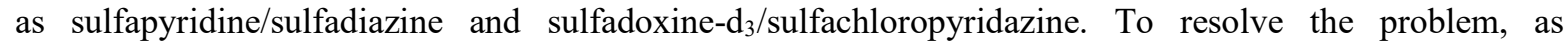
mentioned above (section 2.2), a $250 \mathrm{~mm}$ HPLC column was used in place of $150 \mathrm{~mm}$ column. Regarding sulfathiazole/sulfapyridine- $\mathrm{C}_{6}$ and sulfamethoxypyridazine- $\mathrm{d}_{3} /$ sulfachloropyridazine, different quantification ions were identified as listed in Table 1.

For chromatographic separation of analytes, methanol-water and acetonitrile-water gradient elution programs were applied, and acetonitrile-water mixture was found to be the best separation solvent system. Three different concentrations of formic acid $(0.1,0.5$ and $1 \%, \mathrm{v} / \mathrm{v})$ to improve ionization and peak shape were also investigated and $0.1 \% \mathrm{v} / \mathrm{v}$ was found to be the best formic acid content.

\subsection{Optimization of Sample Preparation}

Different extraction methods to extract sulfonamides from the challenging milk matrix, containing protein and fat, were investigated. Initially a liquid-liquid extraction method, developed by Sun et. al., [41] as an Agilent application note, where water, acetonitrile, sodium sulfate and sodium chloride were used. As it resulted in around 40-45\% recoveries, this method was abandoned. Second method involved an Agilent application note, developed by Gonzalez et. al. [42], where acetonitrile extraction and SPE clean up (Agilent SampliQ SCX) were employed. It resulted in around 50-60\% recoveries. Third one was a modified QuEChERS method, developed by Parab and Amritkar [3], which gave around 40\% recoveries. Finally, the method developed by our group, which was modified from the method-used by Cai et. al. for the extraction of sulfonamides in meat samples, was applied. Its details are given in section 2.3., recoveries were in the range of $91-114 \%$. 
Regarding the extraction solvent, ethyl acetate, acetonitrile and different proportions of acetonitrile and ethyl acetate mixtures were investigated. Acetonitrile:ethyl acetate $(6: 4, \mathrm{v} / \mathrm{v})$ mixture was found to be the best extraction solvent combination.

\subsection{Matrix Effects}

The matrix effect of each compound was determined by comparing the peak area of standard solution and blank milk sample extract spiked at $100 \mathrm{ng} / \mathrm{g}$ concentration before submitting to LC-MS/MS. The matrix effect observed was ranging from $12 \%$ signal suppression for sulfapyridine and $11 \%$ signal enhancement for sulfadiazine. Although IDMS technique was used, in order to be more confident about the results, matrix matched calibration solutions, prepared by adding standard solutions to negative milk extracts to compensate signal enhancement and suppression were applied.

Table 2. Validation data summarized.

\begin{tabular}{|c|c|c|c|c|c|c|c|c|}
\hline \multirow[t]{2}{*}{ Compound } & \multirow{2}{*}{$\begin{array}{l}\text { Correlation } \\
\text { Coefficient }\end{array}$} & \multirow{2}{*}{$\begin{array}{l}\text { LOD } \\
(\mathrm{ng} / \mathrm{g})\end{array}$} & \multirow{2}{*}{$\begin{array}{c}\text { LOQ } \\
(\mathrm{ng} / \mathrm{g})\end{array}$} & \multicolumn{3}{|c|}{ Recovery } & \multirow{2}{*}{$\begin{array}{l}\text { RSD } \\
\text { (intra- } \\
\text { day) }\end{array}$} & \multirow{2}{*}{$\begin{array}{l}\text { RSD } \\
\text { (inter- } \\
\text { day) }\end{array}$} \\
\hline & & & & $15(\mathrm{ng} / \mathrm{g})$ & $\begin{array}{c}25 \\
(\mathrm{ng} / \mathrm{g})\end{array}$ & $\begin{array}{c}40 \\
\text { (ng/g) }\end{array}$ & & \\
\hline SMR & 0.996 & 2.45 & 8.16 & 104.15 & 101.77 & 109.75 & 7.72 & 4.20 \\
\hline SDZ & 0.997 & 2.38 & 7.93 & 108.66 & 104.72 & 106.21 & 5.72 & 2.88 \\
\hline SSX & 0.999 & 2.19 & 7.30 & 105.02 & 97.10 & 94.61 & 6.41 & 7.33 \\
\hline SMX & 0.996 & 2.56 & 8.53 & 100.57 & 99.07 & 102.03 & 7.50 & 8.65 \\
\hline STZ & 0.996 & 1.82 & 6.07 & 107.73 & 98.95 & 96.37 & 5.02 & 5.13 \\
\hline SDM & 0.996 & 2.74 & 9.13 & 110.33 & 101.30 & 102.00 & 3.73 & 14.25 \\
\hline SPD & 0.996 & 2.28 & 7.61 & 109.94 & 103.03 & 101.58 & 6.70 & 3.40 \\
\hline SME & 0.999 & 2.66 & 8.87 & 99.28 & 95.53 & 94.13 & 7.08 & 2.85 \\
\hline SDX & 0.997 & 1.99 & 6.66 & 113.86 & 108.00 & 112.78 & 8.32 & 7.23 \\
\hline SCP & 0.998 & 2.41 & 8.05 & 102.22 & 96.24 & 98.13 & 8.31 & 11.68 \\
\hline SPA & 0.998 & 2.41 & 8.04 & 108.38 & 96.02 & 93.07 & 5.77 & 8.77 \\
\hline SMZ & 0.996 & 2.45 & 8.16 & 99.99 & 98.58 & 90.85 & 8.05 & 7.87 \\
\hline SQX & 0.996 & 2.63 & 8.75 & 103.04 & 98.85 & 96.75 & 4.26 & 1.82 \\
\hline SMP & 0.996 & 2.92 & 9.73 & 102.36 & 98.31 & 93.94 & 5.55 & 3.00 \\
\hline
\end{tabular}

\subsection{Method Validation}

The full IDMS method proposed herein was validated in terms of its performance through limit of detection (LOD), limit of quantification (LOQ), working range, precision, trueness, measurement uncertainty and ruggedness. Results are summarized in Table 2. LODs were estimated at 1.82-2.92 ng/g. A good linearity was obtained (regression coefficient $>0.996$ ) in the range of $10-50 \mathrm{ng} / \mathrm{g}$. Intra-day precision was determined at three different spiked concentrations $(15,25$ and $40 \mathrm{ng} / \mathrm{g}$ each, $\mathrm{n}=3)$, and inter-day precision was obtained at a spiked concentration of $25 \mathrm{ng} / \mathrm{g}$ on each day $(\mathrm{n}=3)$ in 5 different days. Precision values were calculated by one-way analysis of variance (ANOVA) and are summarized in Table 2. The accuracy expressed as recovery determined at three different spiked concentrations $(15,25$ and $40 \mathrm{ng} / \mathrm{g}$ each, $\mathrm{n}=3)$ ranging from $90.85 \%$ to $113.86 \%$. The robustness of the method was tested applying three important parameters, i. e. amount of extraction solvent, amount of milk sample and amount of n-hexane used to remove fat content. Evaluation of robustness was performed by F-test and sulfachloropyridazine and sulfaphenazole, which 
showed significant difference for the amount of milk. Measurement uncertainty of the method was estimated according to EURACHEM/CITAC Guide (Third Edition) and Guide to the Expression of Uncertainty in Measurement (ISO/IEC Guide 98-3:2008), at 95\% confidence level expanded uncertainties ranging from $7.46 \%$ to $12.71 \%$.

\subsection{Analysis of Real Samples}

To test the capability of the developed method, occurrence of sulfonamides on different types of milk in local Turkish markets and also 6 raw milk samples from street vendors were examined. The method was applied to six UHT milk samples and six pasteurized milk samples. Although no sulfonamides were detected in preserved milks, one sample from street vendor contains $7.3 \mathrm{ng} / \mathrm{g}$ sulfisoxazole and another one contains $6.46 \mathrm{ng} / \mathrm{g}$ sulfamethazine.

\section{Conclusion}

In this study, an IDMS method with high accuracy and good precision was developed for sulfonamides in milk, which is a complex matrix of protein, fat and carbohydrate. Sulfonamides are ampholytes having weak basic and acidic characters (pKa 5-7.6). While their acidic character arises from the N-H linkage of the sulfonamide group, the basic character is due to presence of the nitrogen in aniline group. As the acidic character is more dominant, formic acid is added $(0.1 \%)$ to the mobile phase to assist the ionization of the molecules with heated ESI source. This study presents, for the first time, a fully isotope dilution mass spectrometry method, applied for sulfonamides in milk and evaluated by linearity, recovery, day-to-day variation, robustness, limits of detection and quantification, and measurement uncertainty. Recoveries range from $96 \%$ to $108 \%$ at the spiked level of $25 \mathrm{ng} / \mathrm{g}$. This method offers high accuracy, easy operation and low cost, without complex clean up procedures. It was tested on local market milk samples, except two samples from street vendors, which were free of sulfonamides. This method can serve as an effective and easy approach for the determination of sulfonamide residues in milk.

\section{ORCID}

Isin Aydin Unsal: 0000-0002-6005-1315

Murat Tasan: 0000-0003-1490-7626

Taner Gokcen: 0000-0003-3965-6704

Ahmet C. Goren: 0000-0002-5470-130X

\section{References}

[1] W. Baran, E. Adamek, J. Ziemiańska and A. Sobczak (2011). Effects of the presence of sulfonamides in the environment and their influence on human health, J. Hazard. Mater. 196, 1-15.

[2] W. Zhu, J. Yang, Z. Wang, C. Wang, Y. Liu and L. Zhang (2016). Rapid determination of 88 veterinary drug residues in milk using automated TurborFlow online clean-up mode coupled to liquid chromatography-tandem mass spectrometry, Talanta. 148, 401-411.

[3] S. R. Parab and P. N. Amritkar (2012). Development and validation of a procedure for determination of sulfonamide residues in pasteurized milk using modified QuEChERS method and liquid chromatography/tandem mass spectrometry, J. AOAC Int. 95, 1528-1533.

[4] M. Kanda, T. Nakajima, H. Hayashi, T. Hashimoto, S. Kanai, C. Nagano, Y. Matsushima, Y. Tateishi, S. Yoshikawa, Y. Tsuruoka, T. Sasamoto and I. Takano (2015). Multi-residue determination of polar veterinary drugs in livestock and fishery products by liquid chromatography/tandem mass spectrometry, J. AOAC Int. 98, 230-247.

[5] D. Kim, J. O. Choi, J. Kim and D.W. Lee (2003). Application of a Polymeric Solid Phase Extraction for the Analysis of Sulfonamides in Milk by LC/MS, J. Liq. Chromatogr. Relat. Technol. 26, 1149-1159.

[6] R. P. Lopes, D.V. Augusti, F.A. Santos, E.A. Vargas and R. Augusti (2013). Development and validation of an efficient and innovative method for the quantification of multiclass veterinary drugs in milk by using LC-MS/MS analysis, Anal. Methods. 5, 5121.

[7] M. J. García-Galán, M. Silvia Díaz-Cruz, D. Barceló and D. Barceló (2009). Combining chemical analysis and ecotoxicity to determine environmental exposure and to assess risk from sulfonamides, TrAC-Trends Anal. Chem. 28, 804-819.

[8] European commission, Commission regulation (EU) No 37/2010, Off. J. Eur. Union. I.15 (2009).

[9] W. Jiang, Z. Wang, R. C. Beier, H. Jiang, Y. Wu and J. Shen (2013). Simultaneous determination of 13 fluoroquinolone and 22 sulfonamide residues in milk by a dual-colorimetric enzyme-linked immunosorbent assay, Anal. Chem. 85, 1995-1999. 
[10] I. S. Nesterenko, M. A. Nokel and S. A. Eremin (2009). Immunochemical methods for detection of sulfonamides.pdf, $J$. Anal. Chem. 64, 434-444.

[11] H. Sun and H. Qi (2013). Capillary electrophoresis combined with accelerated solvent extraction as an improved methodology for effective separation and simultaneous determination of malachite green, crystal violet and their leucometabolites in aquatic products, Anal. Methods. 5, 267-272..

[12] M. L. Polo-Luque, B. M. Simonet and M. Valcárcel (2013). Solid phase extraction-capillary electrophoresis determination of sulphonamide residues in milk samples by use of C18-carbon nanotubes as hybrid sorbent materials., Analyst. 138, 378691.

[13] M. Vosough and H. Mashhadiabbas Esfahani (2013). Fast HPLC-DAD quantification procedure for selected sulfonamids, metronidazole and chloramphenicol in wastewaters using second-order calibration based on MCR-ALS, Talanta. 113, 6875.

[14] R. Qi, X. Lv, Q. Niu, B. Hu and Q. Jia (2015). Rapid HPLC-DAD quantitation of sulfonamides in honey using poly(methacrylic acid-ethylene dimethacrylate) monolith modified with 3-(trimethoxysilyl)propyl methacrylate-grafted sodium titanate nanotubes, New J. Chem. 39, 6323-6331.

[15] F. Mor, F. Sahindokuyucu Kocasari, G. Ozdemir and B. Oz (2012). Determination of sulphonamide residues in cattle meats by the Charm-II system and validation with high performance liquid chromatography with fluorescence detection, Food Chem. 134, 1645-1649.

[16] A. Tölgyesi, R. Berky, K. Békési, S. Fekete, J. Fekete and V. K. Sharma (2013). Analysis of sulfonamide residues in real honey samples using liquid chromatography with fluorescence and tandem mass spectrometry detection, J. Liq. Chromatogr. Relat. Technol. 36, 1105-1125.

[17] S. Wang, H. Y. Zhang, L. Wang, Z. J. Duan and I. Kennedy (2006). Analysis of sulphonamide residues in edible animal products: a review., Food Addit. Contam. 23, 362-384.

[18] V. F. Samanidou, E. P. Tolika and I. N. Papadoyannis (2008). Chromatographic Residue Analysis of Sulfonamides in Foodstuffs of Animal Origin, Sep. Purif. Rev. 37, 325-371.

[19] K. Bousova, H. Senyuva and K. Mittendorf (2012). Multiresidue automated turbulent flow online LC-MS/MS method for the determination of antibiotics in milk, Food Addit. Contam. Part A. 29, 1901-1912.

[20] S. B. Turnipseed, J. M. Storey, S. B. Clark and K. E. Miller (2011). Analysis of Veterinary Drugs and Metabolites in Milk Using Quadrupole Time-of-Flight Liquid Chromatography-Mass Spectrometry, J Agric Food Chem. 59(14) 7569-7581.

[21] S. B. Clark, S. B. Turnipseed, M. R. Madson, J. A. Hurlbut, L. R. Kuck and J. N. Sofos (2005). Confirmation of sulfamethazine, sulfathiazole, and sulfadimethoxine residues in condensed milk and soft-cheese products by liquid chromatography/tandem mass spectrometry, J. AOAC Int. 88, 736-743.

[22] A. Kaufmann, P. Butcher, K. Maden, S. Walker and M. Widmer (2011). Development of an improved high resolution mass spectrometry based multi-residue method for veterinary drugs in various food matrices, Anal. Chim. Acta. 700, 86-94.

[23] S. Chan, M. F. Kong, Y. C. Wong, S. K. Wong and D. W. M. Sin (2007). Application of isotope dilution gas chromatography-mass spectrometry in analysis of organochlorine pesticide residues in ginseng root, J. Agric. Food Chem. 55, 3339-45.

[24] M. Sargent, R. Harte and C. Harrington (2002). Guidelines for achieving high accuracy in isotope dilution mass spectrometry (IDMS), Royal Society of Chemistry, Cambridge.

[25] Z. Cai, Y. Zhang, H. Pan, X. Tie and Y. Ren (2008). Simultaneous determination of 24 sulfonamide residues in meat by ultra-performance liquid chromatography tandem mass spectrometry, J. Chromatogr. A. 1200, 144-155.

[26] R. Mohamed, Y. A. Hammel, M. H. LeBreton, J. C. Tabet, L. Jullien and P. a Guy (2007). Evaluation of atmospheric pressure ionization interfaces for quantitative measurement of sulfonamides in honey using isotope dilution liquid chromatography coupled with tandem mass spectrometry techniques, J. Chromatogr. A. 1160, 194-205.

[27] A. F. Forti and G. Scortichini (2009). Determination of ten sulphonamides in egg by liquid chromatography-tandem mass spectrometry, Anal. Chim. Acta. 637, 214-219.

[28] L. Verzegnassi, M. C. Savoy-Perroud and R. H. Stadler (2002). Application of liquid chromatography-electrospray ionization tandem mass spectrometry to the detection of 10 sulfonamides in honey, J. Chromatogr. A. 977, 77-87.

[29] I. Varenina, N. Bilandžić, B. S. Kolanović, Đ. Božić, M. Sedak, M. Đokić and I. Varga (2016). Validation of a liquid chromatography-tandem mass spectrometry method for the simultaneous determination of sulfonamides, trimethoprim and dapsone in muscle, egg, milk and honey, Food Addit. Contam. - Part A Chem. Anal. Control. Expo. Risk Assess. 33, 656667.

[30] K. El Hawari, S. Mokh, S. Doumyati, M. Al Iskandarani and E. Verdon (2017). Development and validation of a multiclass method for the determination of antibiotic residues in honey using liquid chromatography-tandem mass spectrometry, Food Addit. Contam. Part A. 34, 582-597.

[31] X. Li, H. Yu, R. Peng and P. Gan (2017). Determination of 19 sulfonamides residues in pork samples by combining QuEChERS with dispersive liquid-liquid microextraction followed by UHPLC-MS/MS, J. Sep. Sci. 40, 1377-1384.

[32] C. H. Wen, S. L. Lin and M. R. Fuh (2017). Determination of sulfonamides in animal tissues by modified QuEChERS and liquid chromatography tandem mass spectrometry, Talanta. 164, 85-91.

[33] S. L. R. Ellison, M. Rosslein, A. Williams, L. A. Konopel'ko and A. V. Garmash (2003). EURACHEM/CITAC Guide: Quantifying Uncertainty in Analytical Measurement, J. Anal. Chem. 58, 191.

[34] ISO 21748:2010, Guidance for the use of repeatability, reproducibility and trueness estimates in measurement uncertainty estimation, ISO 2010.

[35] K. H. Lu, C.Y. Chen and M. R. Lee (2007). Trace determination of sulfonamides residues in meat with a combination of solid-phase microextraction and liquid chromatography-mass spectrometry, Talanta. 72, 1082-1087.

[36] Y. P. Song, L. Zhang, G. N. Wang, J. X. Liu, J. Liu and J. P. Wang (2017). Dual-dummy-template molecularly imprinted polymer combining ultra performance liquid chromatography for determination of fluoroquinolones and sulfonamides in 
pork and chicken muscle, Food Control. 82, 233-242.

[37] U. Konak, M. Certel, B. Şık and T. Tongur (2017). Development of an analysis method for determination of sulfonamides and their five acetylated metabolites in baby foods by ultra-high performance liquid chromatography coupled to highresolution mass spectrometry (Orbitrap-MS), J. Chromatogr. B Anal. Technol. Biomed. Life Sci. 1057, 81-91.

[38] Y. Qin, F. Jatamunua, J. Zhang, Y. Li, Y. Han, N. Zou, J. Shan, Y. Jiang and C. Pan (2017). Analysis of sulfonamides, tilmicosin and avermectins residues in typical animal matrices with multi-plug filtration cleanup by liquid chromatographytandem mass spectrometry detection, J. Chromatogr. B Anal. Technol. Biomed. Life Sci. 1053, 27-33.

[39] W. Zhang, C. Duan and M. Wang (2011). Analysis of seven sulphonamides in milk by cloud point extraction and high performance liquid chromatography, Food Chem. 126, 779-785.

[40] S. Hu, M. Zhao, Y. Xi, Q. Mao, X. Zhou, D. Chen and P. Yan (2017). Nontargeted screening and determination of sulfonamides: A dispersive micro solid-phase extraction approach to the analysis of milk and honey samples using liquid chromatography-high-resolution mass spectrometry, J. Agric. Food Chem. 65, 1984-1991.

[41] A. Technologies (2012). Screening 36 Veterinary Drugs in Animal Origin Food by LC / MS / MS Combined with Modified QuEChERS Method Application Note, 1-10.

[42] C. A. Gonzalez, E. Usher, Karyn M, Brooks, Anne E, Majors and Ronald (2009). Determination of sulfonamides in milk using solid-phase extraction and liquid chromatography-tandem mass spectrometry, Agil. Appl. Note. 5990-3713E 1-6.

\section{A C G publications \\ (C) 2018 ACG Publications}

